\title{
PARAMEXIWECKELIA, a new Genus of Subterranean Amphipod Crustacean (Hadziidae) from Northern México
}

\author{
John R. Holsinger*
}

SUMMARY

Paramexiweckelia, new genus, is described from a grounwater outlet in Cohauila, México. The type-species, by monotypy, is Mexiweckelia particeps Holsinger. Based on the number of its plesiomorphic (ancestral) characters, this genus is the most primitive member of the family Hadziidae from the North American mainland.

\section{INTRODUCTION}

In the years following my description of Mexiweckelia particeps from a groundwater outlet in Coahulia, México (in Holsinger and Minckley, 1971), it has become apparent that this species differs significantly from other species of the genus (i.e., $M$. colei Holsinger and Minckley and M. mitchelli Holsinger) and merits recognition at the generic level (see also Barnard, 1976:425; Bousfield, 1977: 297; Holsinger and Longley, 1980. Paramexiweckelia, new genus, is assigned to the family Hadziidae Karaman (1943) as revived and broadened by Bousfield in 1965 at the Third International Colloquium on Gammarus and Niphargus in Schlitz (Bousfield, 1977) (see also Stock, 1977). Zimmerman and Barnard (1977) also redefined the family, but in a more restricted way than I find acceptable (Holsinger and Longley, 1980.

The description of Paramexiweckelia brings the total number of subterranean freshwater hadziid genera from continental North America to five, including: Mayaweckelia Holsinger

* Department of Biological Sciences Old Dominion University, Norfolk, Virginia 23508, U.S.A. 
(1977a) (two species) from caves on the Yucatán Peninsula in southern México; Mexiweckelia Holsinger and Minckley (two species from a cave and shallow phreatic water in northern México; and Allotexiweckelia Holsinger (one species) and Texiweckelia Holsinger (three species) from the Edwards Aquifer of south-central Texas, U.S.A., one of which has been split off from Mexiweckelia (Holsinger and Longley, 1980). Elsewhere in the greater Caribbean region the family Hadziidae is represented by: Weckelia Shoemaker and Paraweckelia Shoemaker from caves in Cuba; Alloweckelia Holsinger and Peck from a cave in Puerto Rico; Saliweckelia Stock from essentially intestitial, hyperhaline habitats in the Netherlands Antilles; Metaniphargus Stephensen (see also Stock, 1977) from mostly brackish water caves, wells, springs and related groundwater habitats on various islands of the Greater and Lesser Antilles; and Protohadzia Zimmerman and Barnard from shallow marine waters off of Puerto Rico and in the Bimini lagoon (Bahama Islands), which is the only eyed, fully marine hadziid recorded to date from the Caribbean region.

In order to delineate as completely as possible the diagnostic characters of this new genus. I have included illustrations of important structures omitted in the 1971 description of M. particeps.

Paramexiweckelia, new genus (Figs. 1, 2).

Mexiweckelia Holsinger and Minckley, 1971:426 (in part).

\section{Diagnosis}

Without eyes and pigment, of subterranean facies. Interantennal lobe distinct, rounded aneriorly. Antenna 1 longer than antenna 2, more than 50 percent length of body; ethestacs on some flagellar segments; accessory flagellum. 1-segmented. Peduncular segment 4 of antenna 2 with few dorsal spines. Mandible: molar rather prominent, triturative; molar seta absent from left; palp lacking. Maxilla 1: inner plate with apical, plumose setae; outer plates with 9 apical, serrate spines; palp 2-segmented, with few apical spines and/or setae. Maxilla 2: inner plate broader than outer, bearing oblique row of naked setae; both plates with coarse setae apically. Maxilliped: inner plate with bladelike spines and naked and plumose setae apically, and row of plumose setae on inner margin; outer plate bearing row of bladelike spines apically and subapically; palp 4-segmented. Lower lip: outer lobes high, well developed; inner lobes absent; lateral (mandibular) processes long and slender.

Gnathopods not sexually dimorphic, generally similar in both sexes. Propod of gnathopod 1 longer than broad, subrectangu- 


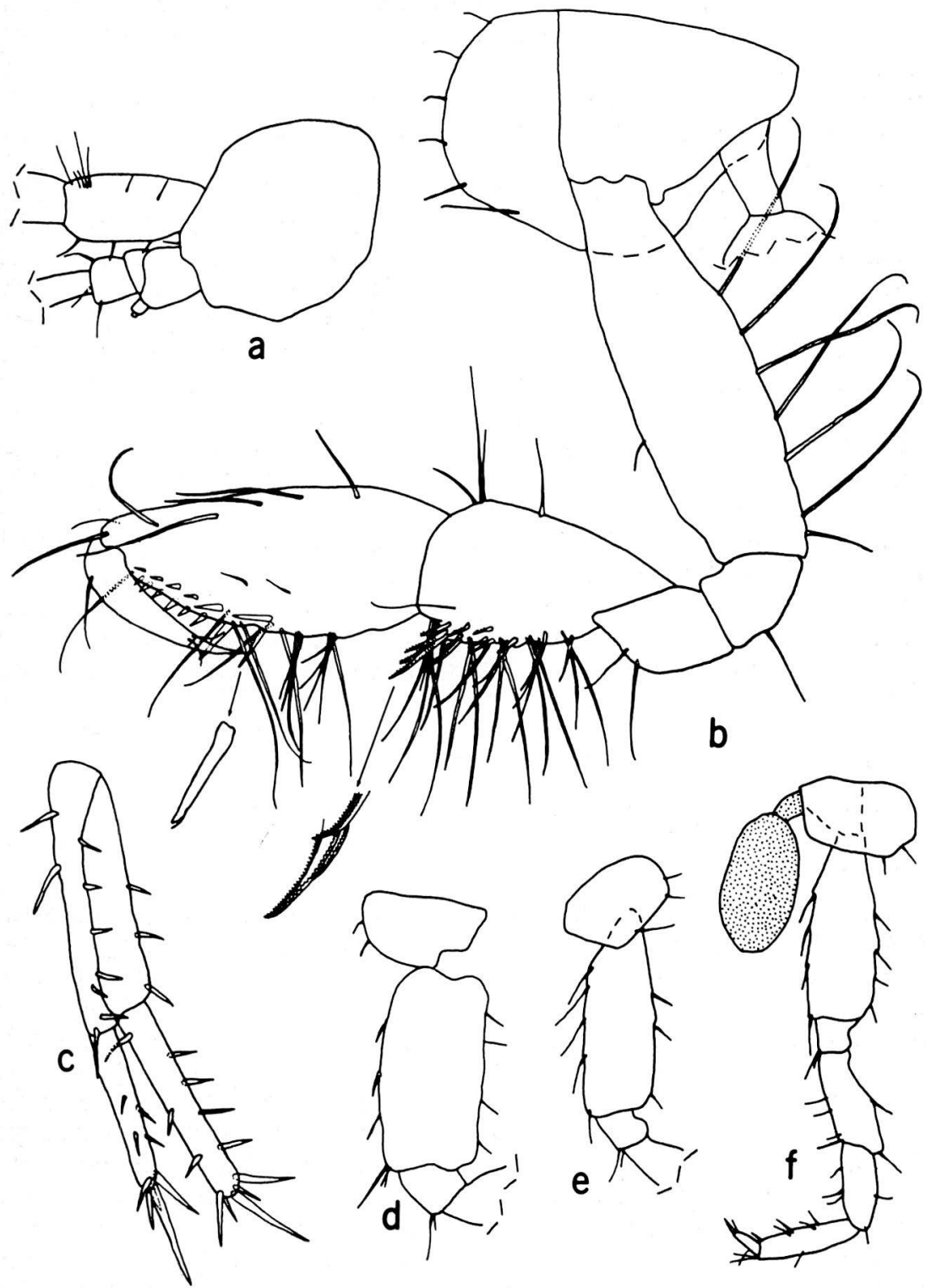

Figure 1. - Paramexiweckelia particeps (Holsinger). - Small spring, Cuatro Ciénegas basin, Coahuila, México. Female $(4.5 \mathrm{~mm})$ : a, head (mouthparts omitted). Male $(5.5 \mathrm{~mm}): \mathrm{b}$, gnathopod 2 (defining angle spine and rastellate setae enlarged); c, uropod 1, Female $(4.0 \mathrm{~mm})$ : d, pereopod 5 (in part); e, pereopod 3 (in part); $\mathrm{f}$, pereopod 4. 
lar; palm short, slightly oblique, with double row of rather strong, distally un-notched spine teeth; posterior margin elongate, with row of setae. Segment 5 of gnathopod 1 as long as propod; posterior margin unlobate and not pubescent, bearing several clusters of small rastellate setae. Propod of gnathopod 2 elongate, longer than propod 1; palm oblique, bearing double row of strong, distally un-notched spine teeth and several long setae; posterior margin as long as or a little longer than palm, bearing several sets of setae. Segment 5 of gnathopod 2 a little shorter than propod; posterior margin unlobate and not pubescent, bearing several clusters of small rastellate setae. Dactyls of gnathopods relatively long, closing beyond defining angles. Coxal plates of gnathopods not enlarged, about as broad as long. Pereopods 3 and 4 subequal, coxal plates shallow. Pereopods 6 and 7 subequal in length, more than 50 percent length of body, longer than pereopod 5. Coxal gills comparatively large, subovate, on pereopods 2-6. Sternal gills lacking. Brood plates small and not fully developed (i.e., not setose) in specimens examined.

Pleonal plates: posterior margins generally straight, with 3 to 4 stiff setae; posterior corners not produced or acuminate; ventral margins without setae or spines. Pleopods biramous, peduncles with 4-5 coupling spines each. Uronite free (not fused), each bearing groups of few spines dorsolaterally. Uropods 1 and 2 biramous, not sexually dimorphic; rami and peduncles bearing normal spines; peduncle of uropod 1 also bearing ventrolateral spines. Uropod 3 comparatively long, biramous (of magniramus type); rami 1-segmented, of equal length but differing slightly in setal pattern; marginal setae plumose. Telson longer than broad; apical margin incised nearly to base; apical lobes and lateral margins bearing slender spines.

Gender is feminine. Type-species, Mexiweckelia particeps Holsinger (by monotypy).

\section{Etymology.}

The generic name, Paramexiweckelia, is derived by a combination of "Para», which is from the Greek meaning «beside, near or by", and "Mexiweckelia», the name of a related Mexican subterranean amphipod genus.

\section{Remarks.}

Although Paramexiweckelia particeps was originally assigned to Mexiweckelia by Holsinger and Minckley (1971), it differs from the latter genus in a number of important characters: a) antenna 1 is approximately 80 percent the length of the body, whereas in Mexiweckelia it is only about 50 percent the length; 

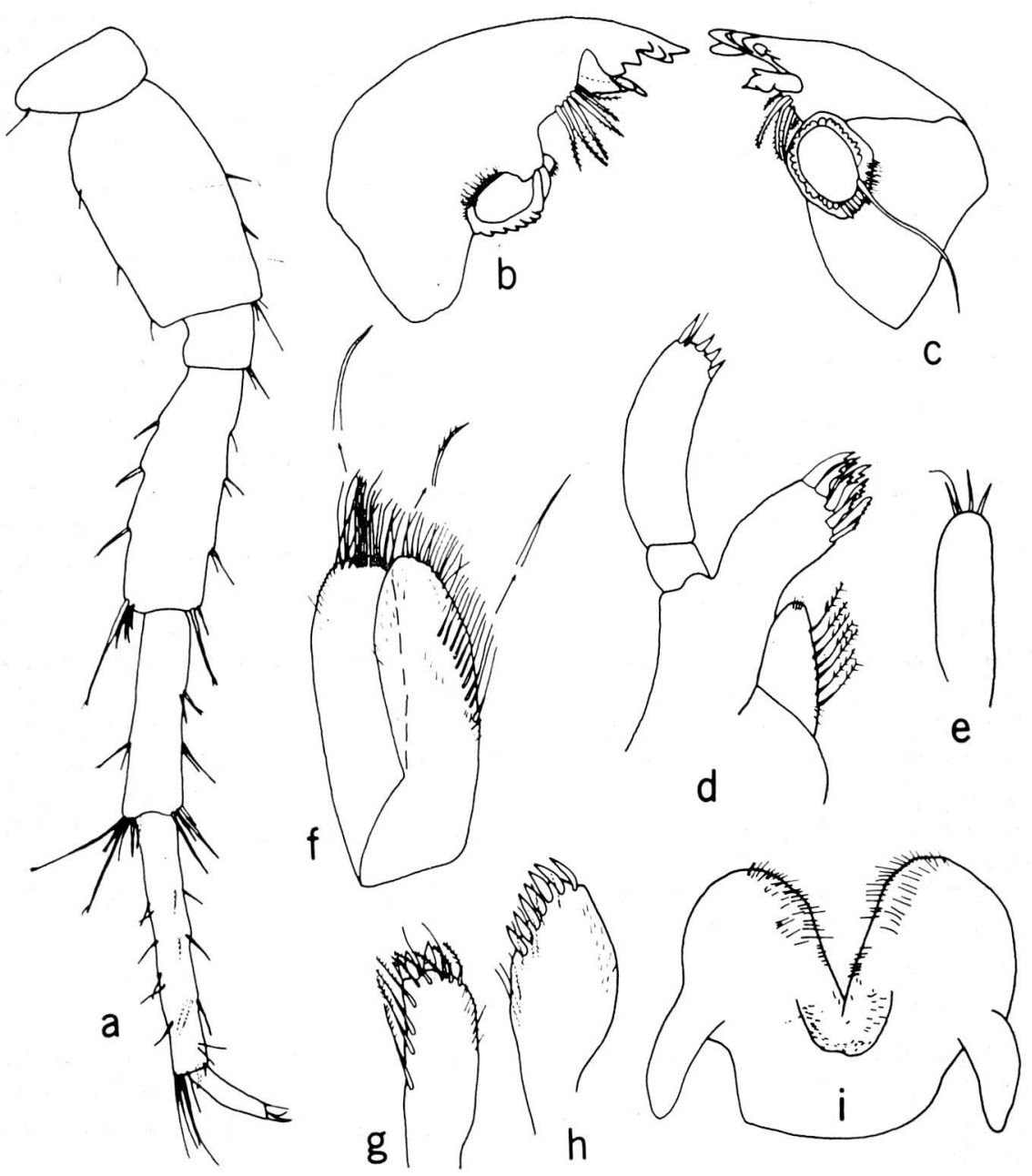

Figure 2. - Paramexiweckelia particeps (Holsinger). - Same locality as fig. 1. Female $(4.0 \mathrm{~mm}):$ a, pereopod 7 . Female $(5.0 \mathrm{~mm}): \mathrm{b}$, c, left and right mandibles; $d$, right maxilla 1 ; e, palp segment 2 of left maxilla $1 ; f$, maxilla 2 (setae enlarged); $g$, inner plate of maxilliped; $h$, outer plate of maxilliped; $i$, lower lip. All mouthparts to same scale. 
b) the accessory flagellum is represented by a single segment, but in Maxiweckelia this structure is vestigial or absent; c) the inner plate of maxilla 1 bears plumose seae and the outer plate has 9 serrate spines in contrast to Mexiweckelia which has naked setae on the inner plate and only 7 serrate spines on the outer plate; d) the gnathopods are not sexually dimorphic as in Mexiweckelia; e) the posterior margin of segment 5 of the gnathopods is unlobate and lacks pubescence but bears small rastellate setae; f) the posterior margins of the pleonal plates have 3 to 4 setae each, but in Mexiweckelia each plate bears a single seta; g) uronites 1 and 2 have more dorsolateral spines; h) the telson is more deeply incised and bears lateral spines.

Several mistakes and omissions in previous descriptions of species of Mexiweckelia should be corrected as follows. In the description of $M$. colei (Holsinger and Minckley, 1971:430-435), the inner plate of maxilla 1 is said to have plumose setae, although fig. $2 \mathrm{~g}$ ( $\mathrm{p}$. 432) correctly depicts these setae as being naked. The peduncle of uropod 1 of $M$. colei bears 2 ventrolateral spines, but these were omitted from fig. $2 b$ (p. 432) by Holsinger and Minckley (1971). In the description of $M$. particeps by Holsinger (in Holsinger and Minckley, 1971: 435-439), the marginal setae of uropod 3 are plumose and not naked as indicated in Fig. 6e (p. 437). In the description of M. mitchelli by Holsinger (1973: 1-5) a ventrolateral spine was omitted from the peduncle of uropod 1 in fig. 1a; the statement «molar without a seta» (p. 5) should read "right molar with seta, ieft without»; the apical setae on the inner plate of maxilla 1 are naked and not plumose as indicated in fig. 11 and page 5; and the posterior margin of segment 4 of gnathopod 1 is partly pubescent and not naked as indicated in fig. 3a.

\section{Taxonomic relationship}

Paramexiweckelia clearly has more plesiomorphic (ancestral) characters than any other genus of the family Hadziidae from the North American mainland. In comparsion with these genera, the plesiomorphic characters include: a) presence of an accessory flagellum; $\mathrm{b}$ ) plumose setae on the inner plate and nine apical spines on the outer plate of maxilla 1; c) lack of sexually dimorphic gnathopods; d) lack of posterior lobes and usually pubescence of either segment 4 or 5 of the gnathopods; e) presence of rastellate setae (or spines) on the gnathopods; f) up to 14 dorsolateral spines on the uronites; and g) deeply incised telson with lateral spines. Although Mayaweckelia has 3-segmented accessory flagellum and completely incised telson, and 
Allotexiweckelia from Texas lacks sexually dimorphic gnathopods, whereas Texiweckelia from Texas contains one species with 14 or 15 spines on the outer plate of maxilla 1 and another species with lateral spines on the telson, all of these genera have more apomorphic characters than Paramexiweckelia.

Because of its relatively large number of plesiomorphic characters, Paramexiweckelia appears to be the most primitive member of the hadziid generic complex in the western part of the greater Caribbean region. Moreover, the presence of rastellate setae or spines on the gnathopods of $P$. particeps is curious inasmuch as this is the only member of the family for which this type of seta or spine is reported. Rastellate setae, however, are common and well developed in he family Crangonyctidae (see Holsinger, 1977b).

\section{ADDENDUM}

Subsequent to the completion of the manuscript, Barnard and Karaman (1982) elevated two of the three species of Texiweckelia from the Edwards Aquifer in Texas to generic level: Texiweckeliopsis (for Texiweckelia insolita) and Holsingerius (for Texiweckelia samacos). This brings the total number of hadziid genera from continental North America to seven, five of which are monotypic.

Barnard, J.L. and G.S. Karaman. 1982. Classificatory revision in gammaridean Amphipoda (Crustacea), Part. 2. Proc. Biol. Soc. Washington, 95 (1): 167-187.

\section{ACKNOWLEDGMENTS}

I am grateful to Drs. J. L. Barnard and E. Bousfield for their advice during the preparation of this paper.

\section{ZUSAMMENFASSUNG}

Paramexiweckelia, eine neue Gattung, wurde von einem Grundwasserausfluss in Coahuila, México beschrieben. Die Typenart, die monotypisch ist, ist Mexiweckelia particeps Holsinger. Auf Grund der Anzahl seinen Abstammungscharacteristiken ist diese Gattung die primitivste in der Familie Hadziidae von Nord Amerikanischen Festland.

\section{LITERATURE CITED}

BARNARD, J.L. 1976 Affinities of Paraniphargus lelouparum (sic) Monod, a blind anchialine amphipod (Crustacea) from the Galapagos Islands. Proc. Biol. Soc. Washington, 89 (36): 421-432.

BOUSFIELD, E. L. 1977. A new look at the systematics of the gammaroidean amphipods of the world. Proc. 3rd Int. Coll. Gammarus and Niphargus, Schlitz, FRG. Crustaceana (suppl.), 4:282-316. 
HOLSINGER, J. R. 1973. Two species of the subterranean amphipod genus Mexiweckelia (Gammaridae) from México and Texas, with notes on the origin and distribution of the genus. Assoc. Mexican Cave Stud. Bull., 5: $1-12$.

HOLSINGER, J. R. 1977a. A new genus and two new species of subterranean amphipod crustaceans (Gammeridae s. lat.) from the Yucatán Peninsula in México. Studies on the Caves and Cave Fauna of the Yucatán Peninsula. Assoc. Mexican Cave Stud. Bull.., 6:15-25.

HOLSINGER, J. R. 1977b. A review of the systematics of the Holarctic amphipod family Crangonyctidae. Proc. 3rd Int. Coll. Gammarus and Niphargus, Schlitz, FRG. Crustaceana (suppl.), 44:244-281.

HOLSINGER, J. R. and W. L. MINCKLEY 1972. A new genus and two new speof subterranean amphipod crustaceans (Gammaridae) from northern México. Proc. Biol. Soc. Washington, 83 (37): 425-444.

HOLSINGER, J.R. and G. LONGLEY, 1980. The amphipod crustacean of an artesian well in Texas. Smithsonian Contr. Zool., 308:1-62.

KARAMAN, S. 1943. Die unterirdischen Amphipoden Südserbiens. Srpska Akad. 308:1-62. Nauk, Posebna Izd. 135, 34(4): 161-312.

STOCK, J. H. 1977 The taxonomy and zoogeography of the hadziid Amphipoda, with emphasis on the West Indian taxa. Studies on the Fauna of Curacao and other Caribbean Islands, 55 (177): 1-129.

ZIMMERMAN, R. J. and J. L. BARNARD 1977. A new genus of primitive marine hadziid (Amphipoda) from Bimini and Puerto Rico. Proc. Biol. Soc. Washington, 95 (1): 167-187. 